\title{
Problem-based Learning: Nursing students' attitude, self-reported competence, tutorial performance and self-directed learning readiness
}

\author{
Judith C. Bruce*1, Melanie Lack², Nthabiseng M. Bomvana ${ }^{2,3}$, Nomawethu Qamata-Mtshali \\ ${ }^{1}$ Faculty of Health Sciences, School of Therapeutic Sciences, University of the Witwatersrand, Johannesburg, South Africa \\ ${ }^{2}$ Department of Nursing Education, Faculty of Health Sciences, University of the Witwatersrand, Johannesburg, South Africa \\ ${ }^{3}$ Chris Hani Baragwanath Nursing College, Johannesburg, South Africa
}

Received: February 13, 2018

DOI: $10.5430 /$ jnep.v8n10p11

\author{
Accepted: April 25, 2018 \\ Online Published: May 7, 2018 \\ URL: https://doi.org/10.5430/jnep.v8n10p11
}

\begin{abstract}
Background and objectives: Problem-based learning (PBL) is widely recognized as progressive pedagogy for the preparation of a range of health professionals. Despite the prominence of PBL in contemporary discussions about the education of future health professionals, its value is increasingly being contested in light of shrinking resources and increasing student enrolments in universities. The objectives were to ascertain Bachelor of Nursing (BN) students' attitude towards the value of PBL as a learning strategy; to determine BN students' degree of certainty about their competence in PBL processes; to determine whether student performance in PBL tutorials improve over four years of study; and to compare the self-directed learning readiness of PBL students to those who are not exposed to PBL.

Methods: The study followed a descriptive and comparative survey design to collect the data. Participants were BN students who were invited to participate in the descriptive survey $(\mathrm{n}=92)$, and purposively selected $(\mathrm{n}=159)$ for comparison between PBL $(\mathrm{n}$ $=54)$ and non-PBL $(\mathrm{n}=105)$ groups.

Results: The majority of students found PBL a stimulating $(59.8 \% ; n=55)$, useful $(65.2 \% ; n=60)$, empowering $(70.6 \% ; n=65)$ and enlightening $(60.8 \% ; \mathrm{n}=56)$ learning strategy; most students $(53.2 \% ; \mathrm{n}=49)$ expressed certainty about their competence in "accessing relevant literature/evidence" but more $(56.3 \% ; \mathrm{n}=52)$ were less certain about their ability to "integrate information into nursing care". First year students performed poorly in PBL tutorials but showed a significant improvement in the final year of study in problem-solving $(p=.0001)$, contribution to the group $(p=.000)$, communication $(p=.000)$, critical thinking $(p=.001)$, learning skills $(p=.001)$, personal growth $(p=.000)$ and leadership skills $(p=.041)$. There was no significant difference between PBL and non-PBL students' overall readiness for self-directed learning $(p=.69)$.

Conclusions: The findings suggest that BN students generally have a positive attitude towards PBL, finding it stimulating, useful, empowering and enlightening in a transformative learning environment. However, fewer students feel that they are competent in the majority of the PBL processes. The biggest learning gains for students during PBL tutorials are in problem-solving, contributions to the group, communication, learning skills, critical thinking, personal growth and leadership. PBL and non-PBL students are similar in their self-directed learning readiness regardless of the learning strategy used.
\end{abstract}

Key Words: Problem-based learning, Self-directed learning, Self-directed learning readiness, Tutorial performance, Learning processes, Attitude, Competence

\footnotetext{
${ }^{*}$ Correspondence: Judith C. Bruce; Email: Judith.bruce @ wits.ac.za; Address: Faculty of Health Sciences, School of Therapeutic Sciences, University of the Witwatersrand, Johannesburg, South Africa.
} 


\section{INTRODUCTION AND BACKGROUND}

Conceptualised over 50 years ago Problem-based Learning (PBL) continues to be used in institutions of higher learning across the globe, mostly in health sciences education - it is widely recognized as progressive pedagogy for the preparation of a range of health professionals. Despite its longevity, PBL continues to feature prominently in discussions about the use of transformative approaches in the education of future health professionals. Being a resource-intensive learning strategy, its value is increasingly being contested in light of shrinking resources and increasing student enrolments in universities. As a university department of nursing education that has adopted PBL for its 4-year Bachelor of Nursing (BN) programme the transformation and learning gains associated with PBL became apparent after a period of 15 years in use. At the inception of PBL, South Africa had undergone significant socio-political change with the abolishment of "Apartheid" - a policy of segregation based on racial grounds. This policy of separate development essentially prevented persons from different racial and cultural backgrounds to socialize, work and learn together. More than just a teaching-learning strategy PBL was considered as an instrument of transformation and reconciliation for this and other nursing schools in South Africa. ${ }^{[1]}$ PBL is thus an important theoretical construct in transforming learning environments.

Within a PBL programme there are expectations that certain skills will be acquired such as: the ability to work together in a group in a cooperative, functional way to perform tasks at hand. According to Werner ${ }^{[2]}$ learning groups are functional when individuals are able to pool their ideas and create effective solutions, improve their ability on information sharing and use best practices. One of the characteristics of PBL is small group tutorials where the dynamics of the group can be steered towards building a high performance group. A function of the group tutorial is to encourage dialogue among its members and to improve interpersonal communication with respect to verbal, non-verbal and cross-cultural skills. PBL tutorials thus provide a platform that helps individuals to improve their communication skills in increments over four years of study in a baccalaureate degree. Furthermore, PBL is also considered as a catalyst for developing abilities to think critically and to solve problems, to be reflective and perform realistic self-assessments, and to become more self-directed in learning. Apart from its necessity for continuous professional development, self-directedness is widely acclaimed as key to students taking responsibility for their own learning in a PBL context. Essential self-directed learning (SDL) attributes include: motivation, self-management, self-control, reflection (on own experiences) and evaluating (own depth of knowledge), with the learner's characteristics being central to SDL. ${ }^{[3]}$

The main conduit for acquiring these skills is well-designed and facilitated PBL tutorials, supported by a range of educational resources. In contemporary education environments, technology and online resources are modifying traditional notions of PBL, highlighting its role in blended learning. Since the use of PBL is likely to continue, one should question whether students' readiness for and acceptance of PBL makes a difference in their ability to acquire these skills; so too are students' attitude towards PBL as a way of learning, which is particularly important in this study context where "learning together" was an artificial construction of students' reality. Recognising that the learning environment for these students needed to be transformed PBL was preferred over traditional teaching-learning strategies and implemented in the BN programme. Empirical evidence about student attitude and how they perform in both the processes and outcomes associated with PBL in transforming learning settings not known; specifically, a coherent body of evidence to inform educational policy and strategies in similar settings is lacking. Results from this study may be used to inform decisions about the future and sustainability of PBL in university nursing schools confronted by competing resources and teaching philosophies.

This paper reports on the findings from original research in PBL conducted at a university nursing school in South Africa. The following research questions were posed:

(1) What are BN students' attitudes towards PBL as a learning strategy?

(2) What is the degree of certainty of these students about their competence in PBL processes?

(3) Does student performance in PBL tutorials differ between the four years of study in their BN degree?

(4) Are PBL students more ready for self-directed learning compared to those who are not exposed to PBL in the $\mathrm{BN}$ degree?

\subsection{Study objectives and variables}

The objectives were to ascertain BN students' attitude towards the value of PBL as a learning strategy; to determine BN students' degree of certainty about their competence in PBL processes; to evaluate student performance in PBL tutorials and determine whether performance improves over four years of study; and to compare the self-directed learning readiness of PBL students to those who are not exposed to PBL. 


\subsection{PBL processes}

The processes that students follow during PBL tutorials are systematic and in this study, include 8-steps to analyse and manage paper-based clinical cases presented during tutorial groups. The process begins with identifying the patient's/community's health problem; generating possible explanations for the problem; prioritize what is important for the patient/community; identify own learning goals; access relevant literature/learning sources; Integrate relevant information into decisions; develop a plan of care/interventions; and collaborate within a team. Collectively, these steps constitute "PBL processes".

\subsection{PBL tutorial performance}

PBL tutorial performance refers to the data derived from an assessment to determine BN students' skill in seven main constructs during tutorials. These constructs: Problem solving; Contributions to the group; Communication; Critical thinking; Learning skills; Personal growth and Leadership skills make up the Tutorial Performance Evaluator (TPE) tool.

\subsection{SDL readiness}

SDL readiness is described as the degree to which an individual possesses the attitudes, abilities and personality characteristics necessary for self-directed learning. ${ }^{[4]}$ In this study it refers to self-management, self-control and desire for learning expressed by nursing students as a measure of SDL readiness.

\subsection{Competence and degree of certainty}

Competence is generally understood as the specific and measurable knowledge, skill, ability and related attributes required for the performance of a task in the context of work and/or learning. In this study competence refers to a student's self-reported ability to execute ("doing") a task within a series of PBL steps or processes - such ability is expressed on a scale from 4 to 1 according to how sure students felt about executing a PBL task.

\section{DESIGN AND METHODS}

A quantitative, descriptive and comparative survey design was used to address the research questions. Table 1 summarises the research methods employed.

Table 1. Summary of research methods employed

\begin{tabular}{|c|c|c|c|}
\hline Research questions & Sample size & Instruments & Data analysis \\
\hline $\begin{array}{l}\text { What are BN students' } \\
\text { attitudes towards the } \\
\text { value of PBL as a } \\
\text { learning strategy? }\end{array}$ & BN students $(n=92)$ & $\begin{array}{l}\text { 7-point semantic differential (SD) } \\
\text { scale of } 5 \text { bipolar adjectives } \\
\text { Scale: }+3 \text { (most positive) to }-3 \\
\text { (most negative) }\end{array}$ & $\begin{array}{l}\text { STATA version } 11 \\
\text { Descriptive statistics; An average } \\
\text { score was calculated to quantify the } \\
\text { attitude as positive or negative. }\end{array}$ \\
\hline $\begin{array}{l}\text { What is the degree of } \\
\text { certainty of these students } \\
\text { about their competence in } \\
\text { PBL processes? }\end{array}$ & BN students $(\mathrm{n}=92)$ & $\begin{array}{l}\text { Questionnaire with a 4-point } \\
\text { Likert scale: } \\
\text { "I am sure I can do this"; } \\
\text { "I think I can do this”; } \\
\text { "I don't think I can do this"; } \\
\text { "I am sure I cannot do this". }\end{array}$ & $\begin{array}{l}\text { STATA version } 11 \\
\text { Descriptive statistics expressed in } \\
\text { frequencies and percentages. }\end{array}$ \\
\hline $\begin{array}{l}\text { Do students' performance } \\
\text { in PBL tutorials differ } \\
\text { between the four years of } \\
\text { study? }\end{array}$ & BN Students $(n=53)$ & $\begin{array}{l}\text { Tutorial Performance } \\
\text { Evaluation (TPE) tool } \\
\text { comprising } 7 \text { learning } \\
\text { constructs and } 34 \text { sub-items. }\end{array}$ & $\begin{array}{l}\text { STATA version } 11 \\
\text { Descriptive and inferential statistics: } \\
\text {-ANOVA to test variance in scores per } \\
\text { year of study ( } p<.05 \text { ); } \\
\text {-Bartlett's to test for equal variances; } \\
\text {-Bonferroni's correction test to adjust } \\
\text { for smaller comparisons }\end{array}$ \\
\hline $\begin{array}{l}\text { Are PBL students more } \\
\text { ready for self-directed } \\
\text { learning compared to } \\
\text { those who are not } \\
\text { exposed to PBL? }\end{array}$ & $\begin{array}{l}\text { BN students }(n=159) \text {, } \\
\text { divided into two } \\
\text { groups: PBL }(n=54) \\
\text { and non-PBL }(n=105)\end{array}$ & $\begin{array}{l}\text { SDLRS }{ }^{[7]} \text {, a } 40 \text {-item, } 5 \text {-point } \\
\text { Likert scale with } 3 \text { sub-scales: } \\
\text { Self-management ( } 13 \text { items); } \\
\text { Desire for learning ( } 12 \text { items); and } \\
\text { Self-control (15 items); the lowest } \\
\text { score is } 1 \text { (strongly disagree) and } \\
\text { highest is } 5 \text { (strongly agree). }\end{array}$ & $\begin{array}{l}\text { STATA version } 11 \\
\text { Descriptive and inferential statistics: } \\
\text {-Nested ANOVA for the analysis of } \\
\text { SDL constructs; } \\
\text {-Fisher's Exact for differences } \\
\text { between smaller samples }(p<.05) \text {. }\end{array}$ \\
\hline
\end{tabular}




\subsection{Study sample}

All students registered for a BN degree from the first year through to the fourth year at the university under study, were invited to participate with the option to withdraw at any point during the research $(n=92 ; 100 \%)$. In the case of the first two questions all students participated $(n=92)$; samples to address questions three and four were smaller $(n=53 ; 57.6 \%$ and $n=54 ; 58.7 \%$ respectively) due to withdrawal from the study, deregistration from the degree or missing data. A comparative sample of $\mathrm{BN}$ students in a lecture-based programme was recruited from a local university after the necessary permission was obtained. Students were purposively selected according to two predominant teaching-learning approaches namely, PBL and lectures (non-PBL), and were assigned to two groups consonant with the teaching-learning approach: a PBL group $(\mathrm{n}=54)$ and a non-PBL group $(\mathrm{n}=105)$. No additional inclusion or exclusion criteria were applied.

\subsection{Data collection}

Data were collected over a period of approximately six months according to the study timetable and the availability of students in the various years of study. Descriptive data to address questions 1, 2 and 3 were collected simultaneously during classroom sessions with students, facilitated by the nurse educator assigned to the class or PBL tutorial group. Timing to collect data for comparative analysis (question 4) had to be synchronised with the calendar and timetables of the second participating university. Hence, the two sets of comparative data were not collected simultaneously but within four weeks of each other.

The setting for data collection was a regular classroom with movable desks and chairs for students to be arranged in tutorial groups. A total of three classrooms were used for data collection. The researchers liaised with class educators/facilitators to hand out the survey tools for completion by students for questions 1,2 and 4 and to both students and PBL facilitators to obtain data for question 3.

\subsection{Instruments}

A 7-point Semantic Differential (SD) scale comprising five bipolar adjective pairs was used to determine students' attitude towards PBL as a learning strategy. Since this was a new approach to teaching and learning adopted by the institution, we were interested in BN students' attitude towards the value of PBL as a learning strategy. By employing an SD scale it would determine whether students report a positive or negative attitude towards PBL. ${ }^{[5]}$ The adjective pairs Stimulating vs. Boring; Easy vs. Difficult; Useful vs. Waste of time; Empowering vs. Disempowering and Enlightening vs. Confusing, were each positively and negatively weighted on a scale ranging from +3 to -3 with 0 representing the middle (neutral value) of the scale. The concepts for the scale were derived from recent PBL literature and were identified in students' journaled experiences of PBL; these were then paired as opposites and were reviewed by two expert nurse educators not involved in the study.

A 4-point Likert scale was used to determine how students' rate their competence in each of the eight steps that constitute the PBL process; the scale enabled the ordinal quantification of students' subjective responses as follows: "I am sure I can do this" (4); "I think I can do this" (3); I don't think I can do this (2); I am sure I cannot do this (1); a score of 4 indicates the highest degree of self-reported certainty regarding competence in the PBL processes through to a score of 1, which indicates the lowest degree of certainty.

The PBL tutorial performance of BN students (from first year to fourth year) was measured using the Tutorial Performance Evaluator (TPE) developed by Lack. ${ }^{[6]}$ A paper-based TPE was administered to BN students immediately after their PBL tutorial sessions for the purpose of self-assessment; simultaneously, the PBL facilitator carried out an assessment on each student on a separate copy of the TPE. Students' performance was rated on a 4-point (0-3) ordinal rating scale with a unique weighting for each of the four points: $0=0 \%, 1=$ $28 \%, 2=69 \%, 3=100 \%$ in the following main constructs: Problem-solving; Contributions to the group; Communication; Critical thinking; Learning skills; Personal growth and Leadership. The data were entered into a computer-based TPE to calculate a combined student and facilitator tutorial score for each student. Each group of constructs and each item within the construct carried an independent weight. The computer programme calculated the weight of construct $\times$ weight of item $\times$ weight of scale $/ 100(\mathrm{WC})(\mathrm{WI})(\mathrm{WS}) / 100$.

For Self-directed Learning Readiness (SDLR) we compared two groups of students: a BPL group and a non-PBL group who were exposed to lecture-based learning at a nearby university. Fisher, King and Tague ${ }^{[7]}$ gave permission to use their SDLR scale. The total scale score is between 40 and 200 ; scores $>150$ indicate readiness for SDL and scores $\leq$ 150 indicate that students are not ready for SDL. ${ }^{[7]}$

\subsection{Pilot testing}

The Likert and SD scales were piloted on a small sample of BN students $(n=10)$ mainly to test comprehension, particularly of the bipolar adjectives, and to trial data analysis. No changes were required. The TPE was previously validated for its content and constructs using subjective judgement by an expert group $(n=8)$ in three rounds of a Delphi survey. ${ }^{[8]}$ Spearman's Rho calculation using nine pairs of tutorial per-

ISSN 1925-4040 E-ISSN 1925-4059 
formance evaluation scores of PBL facilitators and students yielded a score of 0.941 indicating a strong positive correlation.

For the SDL tool Cronbach's alpha was used to determine the internal consistency of the three subscales of the SDLRS: Self-management (0.773), Desire for Learning (0.765) and Self-control (0.736); these contributed to an overall SDLR scale reliability of 0.881 .

\subsection{Data analysis}

A statistical software package, STATA version 11, was used to analyse the data and to produce descriptive and inferential statistics. To analyse tutorial performance data ANOVA tested the variance in scores per year of study in the BN degree. Bartlett's test was used to test for equal variances across samples/student scores; Bonferroni's correction test was used to adjust for smaller comparisons. For the analysis of the three SDL constructs, nested ANOVA was used to test for differences and Fisher's Exact for differences between smaller samples. Statistical significance was set at $p<.05$.

\subsection{Ethical considerations}

Approval for the studies was granted by the university's $\mathrm{Hu}-$ man Research Ethics Committee. The respective education institutions gave permission for the study to be conducted on their premises involving undergraduate students. Individual students gave written consent prior to commencement of the study. All ethical and human rights principles were adhered to throughout the research processes.

\section{RESULTS}

The age range of the sample was between 18 and 28 years and mostly female $(79 \%)$. We present the differences in demographic data and the study results according to the descriptive and research variables around which the research questions were posed. These are: attitude towards the value of PBL, competence in PBL processes, tutorial performance and readiness for SDL.

\subsection{Attitude towards PBL as learning strategy}

A total of $48(52.2 \%)$ fourth year, $33(35.8 \%)$ third year and $11(11.9 \%)$ second year students' responses were analysed. The majority of nursing students felt that PBL was a stimulating $(59.7 \% ; n=55)$ and useful $(65.2 \% ; n=60)$ learning strategy, with most students rating their attitude positively at +3 on the SD scale. Only a small proportion of students $(11.9 \% ; n=11)$ did not value the usefulness of PBL, regarding it as a learning strategy that wastes time. Students' responses to the level of difficulty of PBL i.e. an easy vs. a difficult learning strategy, were mostly neutral; over a third $(34.7 \% ; \mathrm{n}=32)$ found PBL neither too easy nor too difficult and a quarter $(25 \% ; \mathrm{n}=23)$ found PBL difficult. The vast majority $(70.6 \% ; n=65)$ of students reported a positive attitude towards PBL as an empowering learning strategy; $17.3 \%(\mathrm{n}=16)$ were neutral and a small proportion of students $(11.9 \% ; \mathrm{n}=11)$ found PBL disempowering. Similarly, most students $(60.8 \% ; n=56)$ felt that PBL is enlightening; however, $16.3 \%(\mathrm{n}=15)$ students reported that PBL as a learning strategy is confusing (see Table 2).

Table 2. Frequency and percentage of students' ratings of positive and negative adjectives on the SD scale $(\mathrm{n}=92)$

\begin{tabular}{|c|c|c|c|c|c|c|c|c|}
\hline \multirow{2}{*}{ Positive adjectives } & \multicolumn{7}{|c|}{ SD Scale ratings } & \multirow{2}{*}{$\begin{array}{l}\text { Negative } \\
\text { adjectives }\end{array}$} \\
\hline & 3 & 2 & 1 & $\mathbf{0}$ & -1 & -2 & -3 & \\
\hline \multirow{2}{*}{ Stimulating } & $\mathrm{n}=21$ & $\mathrm{n}=17$ & $\mathrm{n}=17$ & $\mathrm{n}=21$ & $n=6$ & $\mathrm{n}=6$ & $n=4$ & \multirow{2}{*}{ Boring } \\
\hline & $22.8 \%$ & $18.5 \%$ & $18.5 \%$ & $22.8 \%$ & $6.5 \%$ & $6.5 \%$ & $4.3 \%$ & \\
\hline \multirow{2}{*}{ Easy } & $\mathrm{n}=4$ & $n=16$ & $\mathrm{n}=17$ & $\mathrm{n}=32$ & $\mathrm{n}=7$ & $\mathrm{n}=11$ & $\mathrm{n}=5$ & \multirow{2}{*}{ Difficult } \\
\hline & $4.3 \%$ & $17.4 \%$ & $18.5 \%$ & $34.8 \%$ & $7.6 \%$ & $11.9 \%$ & $5.4 \%$ & \\
\hline \multirow{2}{*}{ Useful } & $\mathrm{n}=33$ & $n=15$ & $\mathrm{n}=12$ & $\mathrm{n}=21$ & $\mathrm{n}=7$ & $\mathrm{n}=2$ & $n=2$ & \multirow{2}{*}{ Waste of time } \\
\hline & $35.8 \%$ & $16.3 \%$ & $13.1 \%$ & $22.8 \%$ & $7.6 \%$ & $2.2 \%$ & $2.2 \%$ & \\
\hline \multirow{2}{*}{ Empowering } & $\mathrm{n}=28$ & $n=21$ & $n=16$ & $\mathrm{n}=16$ & $\mathrm{n}=5$ & $\mathrm{n}=3$ & $n=3$ & \multirow{2}{*}{ Disempowering } \\
\hline & $30.4 \%$ & $22.8 \%$ & $17.4 \%$ & $17.4 \%$ & $5.4 \%$ & $3.3 \%$ & $3.3 \%$ & \\
\hline \multirow{2}{*}{ Enlightening } & $\mathrm{n}=24$ & $n=20$ & $\mathrm{n}=12$ & $\mathrm{n}=21$ & $n=5$ & $\mathrm{n}=4$ & $n=6$ & \multirow{2}{*}{ Confusing } \\
\hline & $26.1 \%$ & $21.7 \%$ & $13.1 \%$ & $22.8 \%$ & $5.4 \%$ & $4.3 \%$ & $6.5 \%$ & \\
\hline
\end{tabular}

\subsection{Competence in PBL processes}

Students follow the learning processes in PBL tutorials in a systematic manner to manage the patient problem presented to them. In the majority of PBL processes less than half of the students were certain of their competence ("I am sure I can do this"); most expressed certainty about their competence in "accessing relevant literature/evidence" $(53.2 \%$; $n=$
49), followed by "defining a health problem/issue" (48.9\%; $\mathrm{n}=45)$ and "identifying what they need to learn" in order to manage the health issue $(48.9 \% ; n=45)$. Fewer students $(38 \% ; n=35)$ were certain of their ability to integrate the acquired information into nursing care than those who were less certain ("I think I can do this") $(\mathrm{n}=52 ; 56.3 \%)$ (see Table 3). 
Table 3. Self-reported rating of competence in PBL processes of the sample expressed in frequency and percentage $(\mathrm{n}=92)$

\begin{tabular}{|c|c|c|c|c|c|c|c|c|}
\hline \multirow{3}{*}{ Learning processes in PBL } & \multicolumn{8}{|c|}{ Rating scale categories } \\
\hline & \multicolumn{2}{|c|}{$\begin{array}{l}\text { I am sure I can } \\
\text { do this }\end{array}$} & \multicolumn{2}{|c|}{$\begin{array}{l}\text { I think I can } \\
\text { do this }\end{array}$} & \multicolumn{2}{|c|}{$\begin{array}{l}\text { I don't think } \\
\text { I can do this }\end{array}$} & \multicolumn{2}{|c|}{$\begin{array}{l}\text { I am sure I } \\
\text { cannot do this }\end{array}$} \\
\hline & $\mathbf{n}$ & $\%$ & $\mathbf{n}$ & $\%$ & $\mathbf{n}$ & $\%$ & $\mathbf{n}$ & $\%$ \\
\hline Define/formulate the health problem/issue & 45 & 48.9 & 46 & 50.0 & 1 & 1.09 & 0 & 0 \\
\hline Generate hypothesis/explanations for problems & 40 & 43.5 & 49 & 53.2 & 3 & 3.3 & 0 & 0 \\
\hline Prioritize what is important for the patient/community & 42 & 45.6 & 46 & 50.0 & 4 & 4.3 & 0 & 0 \\
\hline Identify what I need to learn & 45 & 48.9 & 44 & 47.8 & 3 & 3.3 & 0 & 0 \\
\hline Access relevant literature/evidence & 49 & 53.2 & 34 & 36.9 & 9 & 9.7 & 0 & 0 \\
\hline Integrate information into nursing care & 35 & 38.0 & 52 & 56.3 & 5 & 5.4 & 0 & 0 \\
\hline Develop a plan of care/interventions. & 40 & 43.5 & 46 & 50.0 & 6 & 6.5 & 0 & 0 \\
\hline Collaborate/work within a team & 42 & 45.6 & 48 & 52.1 & 1 & 1.09 & 1 & 1.09 \\
\hline
\end{tabular}

When we disaggregated the results according to year of study, senior BN students (fourth and third years) reported greater certainty about their competence in all the PBL processes than did junior students. A small proportion of senior students did not think that they were capable of accessing relevant literature $(9.7 \% ; n=9)$ and developing a plan of care/interventions $(6.5 \% ; n=6)$. Less than $2 \%$ of junior students felt that they were not competent to collaborate within a team.

\subsection{PBL tutorial performance}

Responses from 15 (28.3\%) first year, 21 (39.6\%) second year, $8(15.0 \%)$ third year and $9(16.9 \%)$ fourth year BN students were analysed $(n=53)$. First-year students obtained low mean percentages ranging between $15.3 \%$ and $35.7 \%$ with a marked improvement in the second year (55.8\%$81.3 \%)$. Between the first and third year of study students performed poorly in the contributions that they make to the PBL tutorial group. The fourth year students performed consistently better than the others in the all seven constructs with an average percentage of $87 \%( \pm 13.7)$. The difference in performance between first and fourth year students was significant for all constructs as follows: Problem solving ( $\mathrm{df}$ $=3 ; \mathrm{F}=18.62 ; p=.0001)$; Contributions to the group $(\mathrm{df}=$ $3 ; \mathrm{F}=41.86 ; p=.000) ;$ Communication $(\mathrm{df}=3 ; \mathrm{F}=14.16$; $p=.000)$; Critical thinking ( $\mathrm{df}=3 ; \mathrm{F}=23.86 ; p=.001)$; Learning skills $(\mathrm{df}=3 ; \mathrm{F}=33.87 ; p=.001)$; Personal growth $(\mathrm{df}=3 ; \mathrm{F}=25.72 ; p=.000)$ and Leadership skills $(\mathrm{df}=3 ; \mathrm{F}$ $=13.25 ; p=.041)($ see Table 4$)$.

Table 4. Comparison of mean percentages in PBL tutorial performance (TP) from first- to fourth year of study $(\mathrm{n}=53$ )

\begin{tabular}{|c|c|c|c|c|c|c|c|c|c|}
\hline \multirow[t]{2}{*}{ TP: Main Constructs } & \multicolumn{2}{|c|}{$\begin{array}{l}\text { First year average } \\
\text { TP score in \% }\end{array}$} & \multicolumn{2}{|c|}{$\begin{array}{l}\text { Second year } \\
\text { average TP } \\
\text { score in \% }\end{array}$} & \multicolumn{2}{|c|}{$\begin{array}{l}\text { Third year } \\
\text { average TP } \\
\text { score in \% }\end{array}$} & \multicolumn{2}{|c|}{$\begin{array}{l}\text { Fourth year } \\
\text { average TP } \\
\text { score in \% }\end{array}$} & \multirow{2}{*}{$\begin{array}{l}\text { Difference: } \\
\text { 1st and 4th } \\
\text { year } \\
p \text {-value }\end{array}$} \\
\hline & $\%$ & SD & $\%$ & SD & $\%$ & SD & $\%$ & SD & \\
\hline Problem-solving skills & 26.5 & 15.3 & 57.4 & 22.5 & 59.3 & 10.6 & 83.5 & 19.1 & .0001 \\
\hline Contributions to the group & 15.3 & 10.3 & 55.8 & 19.2 & 43.7 & 13.2 & 85.4 & 13.9 & .000 \\
\hline Communication & 35.7 & 26.5 & 81.3 & 25.7 & 64.4 & 13.9 & 87.4 & 15.2 & .000 \\
\hline Critical thinking skills & 23.5 & 12.7 & 60.6 & 24.7 & 58.9 & 17.4 & 89.6 & 13.4 & .001 \\
\hline Learning skills & 26.1 & 13.9 & 67.4 & 20.4 & 59.6 & 13.0 & 91.9 & 11.2 & .001 \\
\hline Personal growth & 35.0 & 14.8 & 67.0 & 20.1 & 56.5 & 14.6 & 93.4 & 5.3 & .000 \\
\hline Leadership & 30.3 & 10.7 & 58.6 & 24.5 & 57.4 & 13.7 & 84.4 & 17.5 & .041 \\
\hline
\end{tabular}

\subsection{Self-directed Learning Readiness}

Demographic data from the two student groups were fairly similar with respect to gender and age. Both PBL and nonBPL groups comprised mostly females ( $80.5 \%$ in each) with a mean age of 22.4 and 22.6 years respectively. Results from the comparative study show that the majority of students in both the PBL (83\%) and non-PBL groups (86\%) reported an overall readiness for SDL. All SDLR scores were more than 150 , which is the quantitative indicator for SDL readiness. ${ }^{\text {[7] }}$ The variance between the scores for PBL and non-PBL students was $<1$ at $163.7( \pm 6.7)$ and $164.2( \pm 5.8)$ respectively and not statistically significant $(p=.69)$. The main effect of 
the teaching-learning approach on their SDL readiness was not significant $[\mathrm{F}(1,151)=.46, p=.50]$.

Results of a further analysis of the SDLR data according to the stage of study (junior and senior) and the SDLR subscales can be seen in Table 5. PBL students reported slightly higher Self-management scores $(50.0 ; \pm 6.7)$ than did nonPBL students $(49.7 ; \pm 5.8)$; however, this difference was not statistically significant $[\mathrm{F}(1,151)=0.05 ; p=.82]$. Similar results were found for Desire to Learn $[\mathrm{F}(1,151)=0.02 ; p$ $=.90]$ and Self-control $[\mathrm{F}(1,151)=1.94, p=.17]$. SDLR between junior students (first and second years) and senior students were not significantly different. The effect of seniority on SDL was not statistically significant within the group $[\mathrm{F}(2,155)=1.11, p=.33]$ and between the PBL and non-PBL groups $[\mathrm{F}(1,155)=0.05, p=.92]$.

Table 5. SDLR scores according to SDL subscales, stage of study and overall SDL readiness of the sample $(\mathrm{n}=159)$

\begin{tabular}{llllll}
\hline & \multicolumn{2}{l}{ Non-PBL group } & PBL group & & \multirow{2}{*}{-values } \\
\cline { 2 - 5 } & $\mathbf{n ~ ( \% )}$ & SDLR & $\mathbf{n ~ ( \% )}$ & SDLR & \\
\hline SDL subscales: & & Mean score (SD) & & Mean score (SD) & \\
Self-management & $105(100)$ & $49.7(5.8)$ & $54(100)$ & $50.0(6.7)$ & .82 \\
Desire for learning & & $49.9(4.8)$ & & $60.1(5.1)$ & .90 \\
Self-control & & $64.6(5.0)$ & & Total score & .17 \\
Stage of study: & & Total score & & .92 \\
Junior & $51(48.6)$ & 166.1 & $32(59.3)$ & 162.9 & .92 \\
Senior & $54(51.4)$ & 162.3 & $22(40.7)$ & 164.5 & \\
Overall SDL readiness: & & Total score & & Total score & .69 \\
\hline
\end{tabular}

\section{Discussion}

The value of PBL from a student attitude perspective yielded various results in the literature depending on the discipline and level of study. Feelings of enjoyment and usefulness of PBL apply mostly to aspects of the learning processes in PBL rather than to PBL as a learning strategy. Finding PBL interesting, enjoyable or engaging as a learning strategy are a few of the descriptors in recent literature that affirm student positivity towards PBL $;^{[9,10]}$ in these studies PBL as a teaching-learning strategy was either new or transformative to bring students from different racial and cultural groups together in a learning group, similar to this study. The anticipated gap in the literature about the value of PBL in transforming learning environments has largely been mitigated. Parts of the learning process that medical and occupational therapy students reportedly enjoy are working in groups and being self-directed, ${ }^{[11]}$ contributions to case discussion and making suggestions about the case, and applying knowledge to complex problems. ${ }^{[10,12]}$ Like their medical counterparts nursing students in PBL programmes tend to be more positive about their educational experience than nonPBL students. ${ }^{[13]}$ Where students do express negative feeling about PBL the literature suggests that these are mainly about students not grasping difficult concepts, which in the absence of explanations by a content expert or a core lecture may create stress and insecurity among students. ${ }^{[10,14]}$ Stress and insecurity may also be as a result of PBL tutorial quality, facilitator competence and tutorial group size, ${ }^{[14]}$ which am-

Published by Sciedu Press plifies students' feelings of incompetence in the learning processes that occur in PBL tutorials. The findings highlight that a positive attitude towards the PBL way of learning is important for student enjoyment of the learning processes and to become competent problem-based learners - good quality tutorials and facilitation of learning within these tutorials are essential to sustain positive attitudes.

With regard to tutorial performance PBL presents many challenges to first year BN students as reflected in an overall mean of $<36 \%$ in all the seven constructs. After an improvement in second year, the tutorial performance of third year BN students showed a decline in six out of seven constructs. This may be attributed to additional workload ${ }^{[1]}$ and the introduction of new subjects such as women's health and psychosocial health. Both these subjects introduce significant clinical work in the third year of study. Tutorial performance among the fourth year students improved significantly in all learning constructs with a mean score range of $83.5 \%$ to $93.4 \%$.

Aspects that students value about PBL are the gains in knowledge and problem-solving skills; $;^{[13,15,16]}$ deep learning and skill development; ${ }^{[17,18]}$ clinical decision-making ${ }^{[9,16]}$ and communication skills. ${ }^{[10,13]}$ Corroborated by evidence from the literature, the findings show that PBL promotes the development of problem-solving, critical thinking and communication skills. The long term gains associated with PBL are the ability to argue and negotiate when interacting with 
others in a multidisciplinary team, and to show assertiveness in a positive way that is present in good leadership skills. ${ }^{[19]}$ PBL enables leadership development as the student assumes different roles in the PBL tutorial (chairperson, case presenter, scribe etc.), and facilitates the contextual integration of knowledge as a learning skill. Personal growth is enhanced and the student becomes more effective when conducting a self-assessment, which at senior level is closely aligned to that of a professional and that is highly reliable. ${ }^{[1]}$ All of these are documented as essential competencies for nurses and other health professionals in 21 st century healthcare environments. The findings from these studies show the benefits of a PBL approach among BN students. They illustrate the difficulties experienced by first-year students and the improvement shown by the fourth-year students. Furthermore, PBL has a positive effect on nurse competence particularly in self-directed learning skills. Cartwright et al. ${ }^{[19]}$ further add that PBL graduates show an increased ability in problem solving and critical thinking skills thereby increasing their cognitive competence compared with graduates from a non-PBL background.

Readiness for SDL is presented in the literature but is mostly inconclusive particularly about the role of a purist vs. a hybrid PBL approach to developing SDL skills. A study by Devi et al. ${ }^{[4]}$ found that medical students who follow a hybrid PBL approach have significantly lower median SDLR scores than those following a traditional, non-PBL approach. However, these authors attribute their findings to the nature of their traditional approach, which means early clinical exposure. Early immersion in clinical work in itself may increase students' motivation thus fostering their SDL skills. Higher SDLR scores in the medical students' study are thus a product of early clinical exposure - whether these scores increase or decrease as the students progress in their studies would be important for educators to know. A study by QamataMtshali ${ }^{[21]}$ found that nursing students' SDLR scores change over four years of study; this change is educationally significant in that students in the PBL group reported higher levels of SDLR than their non-PBL counterparts in the final year of study in a 4-year BN degree. The results in this study suggest that the qualities for SDLR tend to develop between the senior stages of a 4-year degree. These findings support those of Kocaman, Dicle and Ugur, ${ }^{[2]}$ suggesting that self-directed learning is a maturational process that occurs over time in a programme of study. A more recent scoping review of SDL readiness among health professional students confirms that higher SDL readiness is present in students who are further along in their studies. ${ }^{[23]}$

BN students' self-management scores were the lowest of all three SDLR domains. This is not uncommon and may be attributable to students adjusting to university life and struggling to manage the academic and personal demands on their time. ${ }^{[24]}$ This finding is confirmed by studies of paramedics, medical students and nursing students. ${ }^{[4,25-27]}$ PBL workload and time management issues described by Ruiz-Gallardo, Gonzalez-Geraldo and Castano ${ }^{[28]}$ can thwart students' efforts towards improved self-management and require concerted guidance on the part of faculty to assist students on the path to self-directedness in PBL. Overall self-directed learning readiness among the majority of students in both PBL and non-PBL groups yielded total scores above 150 , which indicate an acceptable level of readiness for SDL. ${ }^{[7]}$ Although self-directedness is not significantly different between PBL and non-PBL students in this study, it has been shown in previous studies that students' confidence in and satisfaction with PBL improves, developing life-long learning skills in the process. ${ }^{[9,10,20]}$ The baseline readiness for SDL found in this study may be considered as an important medium for cultivating life-long learning in nursing.

\section{Limitations}

This generalizability of this study's findings is limited to settings of a similar nature only. A longitudinal study of student performance rather than cross-sections thereof would yield more meaningful perspectives of learning gains associated with PBL. Psychometrics of the SD scale is needed in future studies to improve the validity and reliability of the findings. The study sample for between-group comparisons of SDL readiness was small and unequal in size; larger samples and direct measurement of self-directed learning attributes and readiness may have produced different results.

\section{Conclusion}

The findings of this study suggest that $\mathrm{BN}$ students have a positive attitude towards PBL as a learning strategy finding it stimulating, useful, empowering and enlightening. Positive attitudes are the mainstay for student motivation and interest in group learning and to preserve the functionality and quality of PBL tutorial groups in a transforming learning environment. Most students expressed certainty about their competence but in fewer PBL processes; however, they become more assured of their competence towards the final year of study, which is a new and important finding - if students are not competent in the learning steps in PBL, particularly in the early stages of the BN degree, they are unlikely to master the cognitive and attitudinal skills required to achieve the expected outcomes of learning. This may be an area for facilitator or academic intervention and further research. Similarly, significant improvement in student performance in PBL tutorials between the first- and fourth year of study 
is an important return on investment that rivals the benefits associated with traditional teaching. Gains in students' problem-solving, personal growth, learning skills, critical thinking, communication, leadership skills, and group contributions - a proxy for teamwork, affirms the role of PBL as pedagogy. By comparison, both PBL and non-PBL students were to found to have acceptable levels of readiness for selfdirected learning. Although senior PBL students are slightly

\section{REFERENCES}

[1] Lack M, Bruce JC. How nursing students perform in problembased learning tutorials-A South African perspective. Journal of Nursing Education and Practice. 2014; 4 (7): 156-164. https: //doi.org/10.5430/jnep.v4n7p156

[2] Werner A. Groups and Teams. Organisational Behaviour. Pretoria: Van Schaik Publishers; 2011.

[3] Douglass C, Morris SR. Student perspectives on self-directed learning. Journal of the Scholarship of Teaching and Learning. 2014; 14 : 13-25. https://doi.org/10.14434/josotl.v14i1.3202

[4] Devi V, Devan D, Soon PC, et al. Comparison of Self-Directed Learning Readiness among students experiencing Hybrid and Traditional Curriculum. Journal of Clinical and Diagnostic Research. 2012; 6: 1047-1050.

[5] Grove SK, Gray JR, Burns N. Understanding Nursing Research. Building an evidence-based practice. St Louis, Missouri: Saunders Elsevier; 2015.

[6] Lack M. Instrument Validation and Evaluation of Problem Based Learning Tutorial Performance of Undergraduate Nursing Students [Masters Dissertation]. University of the Witwatersrand, Johannesburg; 2009.

[7] Fisher M, King J, Tague G. Self-directed learning readiness scale for nursing education. Nurse Educ Today. 2001.

[8] Lack M, Bruce JC, Becker PJ. Weighting of Items in a Tutorial Performance Evaluation Instrument: Statistical Analysis and Results. Health SA Gesondheid. 2009; 14(1): 1-5.

[9] Kim MJ. Student Satisfaction and Perception of Problem Based Learning Evaluated by Questionnaire. Kosin Medical Journal. 2015; 30: 149-157. https://doi .org/10.7180/kmj . 2015.30.2.149

[10] Chang BJ. Problem-based learning in medical school: A student's perspective. Annals of Medicine and Surgery. 2016; 12: 88-89. PMid:27942381 https://doi.org/10.1016/j.amsu.2016.11 .011

[11] Jay J. Problem-based Learning-a review of students' perceptions in an Occupational Therapy undergraduate curriculum. South African Journal of Occupational Therapy. 2014; 44(1): 56-61.

[12] Bigsby E, McManus IC, McCrorie P, et al. Which medical students enjoy problem-based learning? Education in Medicine Journal. 2013; 5(1): e72-e76.

[13] Rideout E, England-Oxford V, Brown B, et al. A Comparison of Problem-Based and Conventional Curricula in Nursing Education. Adv. Health Scie. Educ. 2002; 7: 3-17.

[14] Szabo Z, Harangi M, Nylander E, et al. How Students Perceive Problem-Based Learning (PBL) Group Tutorials at a Swedish Medical College. MedEdPublish. 2015.

[15] Lian J, He F. Improved performance of students instructed in a hybrid PBL format. Biochem Mol Biol Educ. 2013; 41(1): 5-10. PMid:23382120 https://doi.org/10.1002/bmb. 20666

Published by Sciedu Press better in SDL readiness than their non-PBL counterparts, the findings suggest that their readiness is not attributable to PBL. The implication of this finding is that SDL readiness that is inherent in BN students ought to be optimized by nurse educators through the use of active learning strategies and suitably aligned assessments.

\section{CONFLiCTS OF INTEREST Disclosure}

The authors declare that there is no conflict of interest.
[16] Thabet M, Taha EE, Abood SA, et al. The effect of problem-based on nursing students' decision making skills and styles. Journal of Nursing Education and Practice. 2017; 7(6): 108-116. https: //doi.org/10.5430/jnep.v7n6p108

[17] Gupinar E, Kulac E, Tetik C, et al. Do learning approaches of medical students affect their satisfaction with problem-based learning? Adv Physiol Educ. 2013; 37: 85-88.

[18] Strobel J, van Barneveld A. When is PBL more effective? A Metasynthesis of Meta-analyses Comparing PBL to Conventional Classrooms. Interdisciplinary Journal of Problem-based Learning. 2009; 3(1): 44-58.

[19] Cartwright P, Bruce JC, McInerney P. Effects of problem-based learning on nurse competence: A systematic review. Journal of Nursing Education and Practice. 2017; 7(4): 67-75. https://doi .org/10 .5430/jnep.v7n4p67

[20] Khan N, Ghani N, Khan A, et al. Perceptions of Nursing Students about Problem Based Learning (PBL) in Nursing Institutions of Peshawar, KPK, Pakistan. International Journal of Innovative Research and Development. 2015; 4(1): 278-284.

[21] Qamata-Mtshali N. Problem-based Learning vs. traditional curricula: A comparative study of nursing students' self-directed learning readiness [Masters Dissertation]. University of the Witwatersrand, Johannesburg; 2011.

[22] Kocaman G, Dicle A, Ugur A. Facilitating technology-enhanced Problem Based Learning in assigning Conventional Learning in a PBL Middle School curriculum. J. Nurs. Educ. 2009; 1: 133.

[23] Slater CE, Cusick A. Factors related to self-directed learning readiness of students in health professional programs: a scoping review. Nurs Educ Today. 2017; 52: 28-33. PMid:28229917

[24] Abraham RR, Fisher M, Kamath A, et al. Exploring the first year undergraduate medical students' self-directed learning readiness for physiology. Adv Physiol Educ. 2011; 35: 393-395. PMid:22139776 https://doi.org/10.1152/advan.00011.2011

[25] Williams B, Boyle M, Winship C, et al. Examination of self-directed learning readiness of paramedic undergraduates: A multi-institutional study. Journal of Nursing Education and Practice. 2012; 3(2): 102111. https://doi.org/10.5430/jnep.v3n2p102

[26] Said AB, Ghani N, Khan A, et al. Examination of self-directed learning readiness among Baccalaureate Nursing Students in Peshawar Pakistan. International Journal of Innovative Research and Development. 2015; 4: 257-262.

[27] Yang G, Jiang X. Self-directed learning readiness and nursing competency among undergraduate nursing students in Fujian province of China. International Journal of Nursing Sciences. 2014; 1: 255-259. https://doi.org/10.1016/j.ijnss.2014.05.021

[28] Ruiz-Gallardo J, Gonzalez-Geraldo JL, Castano S. What are our students doing? Workload, time allocation and time management in PBL instruction. A case study in Science Education. Teaching and Teacher Education. 2016; 53: 51-62. https://doi.org/10.101 $6 / j$.tate.2015.10.005 